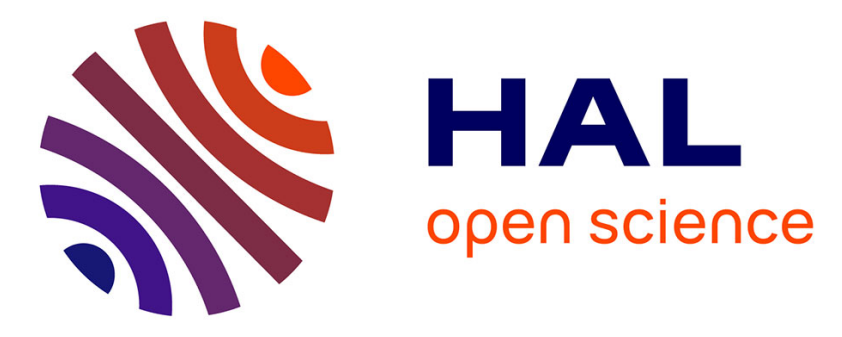

\title{
Les épanchements pleuraux parapneumoniques : épidémiologie, diagnostic, classification, traitement
}

Julien Letheulle, M. Kerjouan, F. Bénézit, B. de Latour, P. Tattevin, C. Piau, H. Léna, B. Desrues, Y. Le Tulzo, S. Jouneau

\section{- To cite this version:}

Julien Letheulle, M. Kerjouan, F. Bénézit, B. de Latour, P. Tattevin, et al.. Les épanchements pleuraux parapneumoniques : épidémiologie, diagnostic, classification, traitement. Revue des Maladies Respiratoires, 2015, 32 (4), pp.344-357. 10.1016/j.rmr.2014.12.001 . hal-01117905

HAL Id: hal-01117905

https://hal-univ-rennes1.archives-ouvertes.fr/hal-01117905

Submitted on 22 Apr 2015

HAL is a multi-disciplinary open access archive for the deposit and dissemination of scientific research documents, whether they are published or not. The documents may come from teaching and research institutions in France or abroad, or from public or private research centers.
L'archive ouverte pluridisciplinaire HAL, est destinée au dépôt et à la diffusion de documents scientifiques de niveau recherche, publiés ou non, émanant des établissements d'enseignement et de recherche français ou étrangers, des laboratoires publics ou privés. 


\title{
Fascicule rouge
}

Rubrique : Revue générale

Les épanchements pleuraux parapneumoniques : épidémiologie, diagnostic, classification, traitement

Julien Letheulle ${ }^{1}$, Mallorie Kerjouan ${ }^{2}$, François Benezit ${ }^{2}$, Bertrand De Latour ${ }^{3}$, Pierre Tattevin ${ }^{1}$, Caroline Piau ${ }^{4}$, Hervé Léna ${ }^{2}$, Benoît Desrues ${ }^{2}$, Yves Le Tulzo ${ }^{1}$ et

Stéphane Jouneau ${ }^{2,5}$.

${ }^{1}$ Service de maladies infectieuses et réanimation médicale, Université de Rennes 1, hôpital Pontchaillou, 2 rue Henri le Guilloux, 35033 Rennes Cedex 9, France

${ }^{2}$ Service de pneumologie, Université de Rennes 1, hôpital Pontchaillou, 2 rue Henri le Guilloux, 35033 Rennes Cedex 9, France

${ }^{3}$ Service de chirurgie thoracique, Université de Rennes 1, hôpital Pontchaillou, 2 rue Henri le Guilloux, 35033 Rennes Cedex 9, France

${ }^{4}$ Laboratoire de bactériologie, Université de Rennes 1, hôpital Pontchaillou, 2 rue Henri le Guilloux, 35033 Rennes Cedex 9, France

5 IRSET UMR 1085, Université de Rennes 1, 2 avenue du Professeur Léon Bernard, 35043

Rennes Cedex 9, France

Titre court : Épanchements parapneumoniques

\author{
Auteur-correspondant : \\ Dr Julien Letheulle \\ Service de maladies infectieuses et réanimation médicale, Hôpital Pontchaillou, \\ 2 rue Henri Le Guilloux, 35033 Rennes cedex 9. \\ Tel : 02.99.28.42.48 / Fax : 02.99.28.41.64 \\ Julien.LETHEULLE@chu-rennes.fr
}

Intérêts en lien avec le thème du manuscrit : aucun 


\section{RESUME}

Les épanchements pleuraux parapneumoniques représentent la principale étiologie des pleurésies infectieuses. Leur incidence est en constante augmentation. Bien qu'ils soient qualifiés de "parapneumoniques", l'épidémiologie microbienne est différente de celle des pneumonies avec notamment une plus grande fréquence des germes anaérobies. La ponction pleurale exploratrice représente l'étape diagnostique centrale qui permet de distinguer les épanchements parapneumoniques compliqués et non compliqués. Seuls les épanchements parapneumoniques compliqués doivent faire l'objet d'un traitement évacuateur reposant sur la mise en œuvre de ponctions pleurales répétées, d'un drainage thoracique ou d'une prise en charge chirurgicale. Le choix de la technique évacuatrice première reste débattu car il existe peu d'études prospectives comparatives. L'utilisation d'agents fibrinolytiques n'a pas fait la preuve de son efficacité sauf lorsqu'ils sont utilisés en association à la DNAse. L'antibiothérapie doit être systématique, précoce et couvrir les germes anaérobies, sauf en cas d'infection à pneumocoque. Il existe peu de données sur la place de la kinésithérapie qui reste largement utilisée. La mortalité est élevée et directement influencée par les comorbidités sous-jacentes.

Mots clés : épanchement pleural parapneumonique, empyème pleural, infection pleurale, drainage thoracique, ponction pleurale, chirurgie thoracique. 
Parapneumonic pleural effusions : Epidemiology, diagnosis, classification and management

\begin{abstract}
:
Parapneumonic pleural effusions represent the main cause of pleural infections. Their incidence is constantly increasing. Although considered as parapneumonic, their microbial epidemiology is different from pneumonia with higher prevalence of anaerobic bacteria. The first thoracentesis is the most important diagnostic stage because it allows distinguishing complicated from not complicated parapneumonic effusions. Only complicated parapneumonic effusions need to be evacuated. Therapeutic evacuation modalities include repeated therapeutic thoracentesis, chest tube drainage or thoracic surgery. The choice of the first-line evacuation treatment is still controversial and there are few prospective controlled studies. The efficiency of the use of fibrinolytics agents is not established except when they are combined with DNase. Antibiotics are mandatory; have to be initiated as fast as possible and active against anaerobic bacteria except for pneumococcal infections. There are few data on the use of chest physiotherapy which remains widely used. Mortality is still high and is influenced by underlying comorbidities.
\end{abstract}

Key-words:

Parapneumonic pleural effusion, pleural empyema, pleural infection, chest tube drainage, thoracentesis, thoracic surgery. 


\section{Introduction}

Le terme pleurésie infectieuse (PI) correspond à l'apparition entre les deux feuillets pleuraux d'un liquide soit macroscopiquement purulent, alors appelé empyème (Figure 1), soit macroscopiquement non purulent mais présentant des caractéristiques bactériologiques ou biochimiques témoignant d'une invasion microbienne [1].

Les étiologies des PI sont multiples et correspondent à des mécanismes physiopathologiques distincts. Il est classique de distinguer les étiologies des PI en fonction de leur porte d'entrée.

Les PI d'origine pulmonaire représentent 55 à $73 \%$ des étiologies [2-6]. Dans la grande majorité des cas, elles font suite à l'invasion par des agents pathogènes de l'espace pleural à partir d'un foyer parenchymateux contigu et sont alors appelées épanchements pleuraux parapneumoniques (EPP) [4].

Les autres étiologies de PI, moins fréquentes, ne seront pas abordées dans cet article. Elles correspondent aux PI par inoculation directe (postopératoires, post-traumatiques ou iatrogènes) ou font suite à processus infectieux médiastinal ou sous-diaphragmatique. Les PI hématogènes sont exceptionnelles [3].

- Épidémiologie et facteurs de risque

Plusieurs études épidémiologiques récentes ont montré une augmentation de l'incidence des EPP et des empyèmes au cours des deux dernières décennies, y compris après ajustement sur l'âge [7, 8]. Cette augmentation concerne principalement les empyèmes pleuraux médicaux (principalement parapneumoniques) alors que l'incidence des empyèmes pleuraux chirurgicaux est relativement stable [8].

Les EPP représentent la cause la plus fréquente d'épanchement pleural exsudatif [9]. Un EPP est mis en évidence dans $36 \%$ à $57 \%$ des cas de pneumopathies bactériennes [10-12] et dans $20 \%$ des cas de pneumonies virales ou à mycoplasme [13]. La survenue d'un empyème est plus rare et complique une pneumonie dans moins de $5 \%$ des cas $[14,15]$. Les empyèmes ne représentent que 5 à $10 \%$ des EPP [4].

Les EPP sont plus fréquents aux deux extrêmes de la vie [8, 16, 17]. L'existence d'une ou plusieurs comorbidités sous-jacentes est retrouvée chez plus de deux tiers des malades [6]. Ces comorbidités sont principalement représentées par les pathologies à l'origine de pneumopathies d'inhalation, expliquant la fréquence des germes anaérobies et des germes commensaux de la sphère oropharyngée : maladies neurologiques centrales, états grabataires, troubles psychiatriques graves, alcoolisme, reflux gastro-œsophagien [18]. La présence d'un mauvais état dentaire est rarement précisée dans les études : $10 \%$ dans une étude prospective portant sur 119 patients atteints d'empyème [19]. Les autres comorbidités sont constituées par les pathologies responsables d'un état d'immunosuppression telles que les pathologies néoplasiques, le diabète, l'alcoolisme et les hépatopathies [6, 17, 19-22].

Enfin, la prise de traitements immunosuppresseurs et d'anti-inflammatoires non stéroïdiens peut favoriser la survenue des PI par l'intermédiaire d'une immunodépression mais également en rendant la symptomatologie initiale moins bruyante et en favorisant donc l'invasion pleurale [18, 23]. 
- Données microbiologiques

Bien qu'il s'agisse d'infections parapneumoniques, l'épidémiologie bactérienne des pleurésies infectieuses est différente de celle des pneumopathies infectieuses [19,24]. Ceci pourrait être en partie expliqué par l'acidité et l'hypoxie du liquide pleural infecté favorisant le développement des germes à métabolisme anaérobie [25] et par le fait que certaines bactéries (streptocoques et staphylocoques en particulier) possèdent un tropisme particulier pour la surface pleurale [26].

Les étiologies microbiennes des EPP ont évolué au cours du temps [27, 28]. La pleurésie à pneumocoque qui représentait 60 à $70 \%$ des cas avant l'ère de l'antibiothérapie [29] est devenue plus rare depuis la systématisation de l'antibiothérapie et n'est retrouvée actuellement que dans $10 \%$ des cas [30]. À l'inverse, les infections à bactéries à Gram négatif et à germes anaérobies ont vu leur incidence augmenter [6,31].

Par ailleurs, la flore microbienne dépend principalement du terrain. Les infections polymicrobiennes et à germes anaérobies sont davantage rencontrées en cas de pneumopathie d'inhalation, les cultures bactériennes retrouvant jusqu'à $86 \%$ de germes anaérobies lorsque l'on considère uniquement les pneumopathies d'inhalation [32]. Les infections à bacilles à Gram négatif sont plus fréquentes chez les patients atteints de comorbidités [20]. Klebsiella pneumoniae est plus fréquemment identifié chez les sujets diabétiques [20] et Haemophilus influenzae est plus souvent rencontré chez l'enfant [33].

Tous les germes responsables de pneumopathies infectieuses sont susceptibles de donner un EPP [9] mais le risque relatif de développer un EPP et d'évoluer vers l'empyème varie selon le germe en cause. Les EPP compliquant une légionellose [34, 35] ou une infection à Mycoplasma pneumoniae [13] sont rares, peu abondants et évoluent rarement vers l'empyème [24, 36]. Environ $50 \%$ des pneumonies à Streptococcus pneumoniae s'accompagnent d'épanchements mais moins de $5 \%$ deviennent purulents $[37,38]$. À l'inverse, $40 \%$ des pneumopathies à Staphylococcus aureus s'accompagnent d'épanchements, dont $20 \%$ deviennent purulents. Enfin $50 \%$ des pneumopathies à bacilles à Gram négatif et $35 \%$ des pneumopathies à germes anaérobies se compliquent d'épanchements, dont $90 \%$ deviennent purulents [14]

Dans la série de Maskell et coll. concernant 434 patients [22, 24], la culture pleurale était positive chez 250 sujets $(58 \%)$. Les streptocoques du groupe milleri étaient les germes les plus fréquemment identifiés (21\%), suivis de Streptococcus pneumoniae (19\%), des bactéries anaérobies (18\%), de Staphylococcus aureus (14\%) et des bacilles à Gram négatif (11\%).

En cas d'infection nosocomiale, Staphylococcus aureus est le premier cocci à Gram positif retrouvé et présente une résistance à la méticilline dans deux tiers des cas [24]. Les infections à bacilles à Gram négatif sont également plus fréquentes, notamment dans les services de réanimation et de soins intensifs [31].

Les empyèmes d'origine fongique sont beaucoup plus rares [28]. Ils surviennent essentiellement en contexte nosocomial, chez des patients immunodéprimés ayant reçu une antibiothérapie à large spectre. Les infections à Candida sont les plus souvent rencontrées, devant les infections à Aspergillus. La mortalité est dans ce cas supérieure à $70 \%$ [39].

Enfin, la culture pleurale peut être négative dans environ $40 \%$ des cas [24]. Cependant, l'utilisation de techniques d'identification par PCR est plus sensible que la culture standard [40, 41] et permet l'identification des infections "décapitées" par une antibiothérapie préalable 
(pneumocoque) ou des germes difficiles à cultiver (anaérobies) [24]. Dans la série de Maskell et coll. [24], la PCR, associée à la culture standard, permettait une identification de l'agent causal dans $75 \%$ des cas.

- L'incidence des EPP est en augmentation.

- Les EPP surviennent principalement chez les patients présentant des comorbidités sousjacentes.

- Les germes les plus fréquemment rencontrés sont les germes anaérobies : streptocoques du groupe milleri et bacilles à Gram négatif.

- La pleurésie à pneumocoque est devenue moins fréquente.

- Staphylococcus aureus est le premier germe rencontré en cas d'EPP nosocomial.

- Physiopathologie des épanchements parapneumoniques

Le développement d'un empyème à partir d'un foyer pneumonique sous-pleural représente un processus continu comportant plusieurs stades (Figure 2) [42].

Le premier stade, dit exsudatif, est lié à une augmentation de la perméabilité capillaire secondaire à l'atteinte des cellules endothéliales par les cellules inflammatoires au sein du foyer pneumonique. L'accumulation de liquide dans l'interstitium pulmonaire est responsable d'une augmentation du gradient de pression entre le secteur interstitiel et l'espace pleural, à l'origine de mouvements liquidiens vers la cavité pleurale entre les cellules mésothéliales de la plèvre viscérale [16]. Si la formation de liquide dépasse les capacités de résorption des vaisseaux lymphatiques de la plèvre et du poumon, un épanchement pleural apparait. Il en résulte la formation d'un exsudat stérile avec liquide non visqueux. Le pH et la glycopleurie sont normaux et le taux de LDH est peu augmenté [10]. L'épanchement parapneumonique est alors qualifié de non compliqué [10].

Au cours de la seconde phase, dite fibrinopurulente, les bactéries vont adhérer aux cellules mésothéliales puis pénétrer dans le liquide pleural après desquamation de ces dernières ou par rupture de micro-abcès sous-pleuraux [1]. Les bactéries sécrètent des facteurs chémotactiques (IL-8, TNF $\ldots$...) attirant les cellules inflammatoires dans l'espace pleural et induisent une activation de la cascade de la coagulation et une inhibition de l'activité fibrinolytique aboutissant à une accumulation de fibrine dans l'espace pleural [43]. Le liquide prend alors un aspect plus épais et visqueux et peut devenir macroscopiquement purulent (empyème). Le pH pleural diminue par production de lactates et de $\mathrm{CO}_{2}$, de même que la glycopleurie en rapport avec la glycolyse bactérienne et des cellules inflammatoires [44]. Le taux de LDH devient élevé. L'examen bactériologique est positif à l'examen direct ou en culture (en l'absence d'antibiothérapie préalable). L'épanchement parapneumonique est alors qualifié de compliqué [10].

La troisième phase, dite d'organisation, correspond à la prolifération des fibroblastes au sein de la cavité pleurale. L'accumulation de fibrine et de collagène est responsable de la formation de loculations au sein de l'épanchement pleural qui devient cloisonné (Figure 3) et de l'épaississement des feuillets pleuraux (pachypleurite) empêchant la ré-expansion pulmonaire, à l'origine de séquelles restrictives [1, 42].

En l'absence de traitement, l'empyème évolue classiquement vers la fistulisation bronchique ou 
pariétale (empyema necessitatis) [1].

- Diagnostic des EPP et empyèmes

- Place de la ponction pleurale exploratrice

Les données cliniques et biologiques ne permettent pas de discriminer les EPP compliqués des EPP non compliqués $[9,10]$.

La ponction pleurale exploratrice constitue donc une étape essentielle dans le diagnostic des EPP. Elle permet en effet d'établir le diagnostic positif, d'identifier le ou les germes en cause et de classer l'épanchement pleural en différents stades guidant la prise en charge thérapeutique : EPP non compliqué, EPP compliqué ou empyème. Un retard à la réalisation de la ponction pleurale exploratrice est par ailleurs associé à une durée d'hospitalisation plus longue [12].

Les hémocultures permettent l'identification du germe en cause dans seulement $10 \%$ des cas [45], alors que les autres examens microbiologiques sont le plus souvent négatifs, ce qui témoigne de l'importance de la ponction pleurale diagnostique [22]. L'examen cytobactériologique des crachats ou les prélèvements fibroscopiques peuvent également être positifs et concorder avec la bactériologie pleurale $[1,15,18]$.

- Diagnostic des empyèmes

La présence de liquide macroscopiquement purulent est suffisante pour porter le diagnostic d'empyème, l'unique diagnostic différentiel " visuel " étant le chylothorax ou pseudochylothorax [1]. Seul l'examen bactériologique est alors nécessaire en vue d'identifier le ou les germes en cause. Cependant, même en présence de pus franc, l'examen bactériologique peut être négatif dans 18 à $30 \%$ des cas [27]. Une odeur nauséabonde oriente vers la présence de germes anaérobies [18].

\section{- Diagnostic des EPP}

En cas de liquide non purulent (trouble ou clair), l'analyse du liquide pleural doit comporter le dosage des protides, $\mathrm{LDH}$, glucose et $\mathrm{pH}$, une numération cellulaire et un examen bactériologique (examen direct et culture sur milieux aérobie et anaérobie avec recherche de BK).

Les épanchements parapneumoniques sont des exsudats. La présence d'un transsudat exclut le diagnostic d'épanchement pleural parapneumonique [2]. Il faut toutefois préciser qu'un exsudat peut coaguler dans la seringue de prélèvement avec formation d'un surnageant présentant les caractéristiques d'un transsudat. Leur cytologie est marquée par une prédominance de polynucléaires neutrophiles qui peuvent être altérés. La prédominance d'un autre type cellulaire (lymphocytes) est en défaveur d'une étiologie bactérienne [2]. Cependant, la cytologie ne permet pas de distinguer les EPP non compliqués des EPP compliqués [9].

L'examen bactériologique de tout épanchement pleural doit être systématique. La mise en évidence de germes dans le liquide pleural affirme le diagnostic d'EPP compliqué. L'ensemencement du liquide pleural dans des flacons d'hémoculture permet d'augmenter la rentabilité diagnostique [46]. 
Les paramètres biochimiques permettant de définir l'épanchement compliqué et de prédire l'évolution défavorable en l'absence de drainage sont le taux de $\mathrm{LDH}$, le $\mathrm{pH}$ et la glycopleurie. La supériorité de la mesure du $\mathrm{pH}$ a été démontrée par une méta-analyse regroupant sept études et retrouvant une valeur seuil de 7,28 au-dessous de laquelle l'évolution semble défavorable en l'absence de traitement évacuateur [47]. Toutefois, l'acidose pleurale nécessite en théorie d'être interprétée en fonction d'une acidose systémique éventuelle [48] et peut être mise en défaut en cas d'infection à Proteus mirabilis qui peut induire une alcalose pleurale par sécrétion d'ammoniac [49]. La glycopleurie est directement corrélée à la valeur du pH et peut donc être utilisée en l'absence de possibilité de mesure du pH [50].

Enfin, il faut garder à l'esprit la possibilité de variations significatives des paramètres biochimiques ( $\mathrm{pH}$ et $\mathrm{LDH})$ entre les différentes loculations au sein d'un même épanchement pleural [51]. Ainsi la valeur du pH pleural peut varier selon les différentes loculations [52].

- La ponction pleurale constitue l'étape diagnostique indispensable.

- L'examen du liquide pleural doit être macroscopique (aspect purulent ou non), biochimique ( $\mathrm{pH}$, glycopleurie, $\mathrm{LDH}$ ), cytologique (recherche de polynucléaires altérés) et bactériologique (examen direct et culture bactérienne).

\section{- Définitions et classifications}

La classification la plus détaillée est celle établie par Light en 1995 qui distingue sept stades de sévérité croissante [36]. Il s'agit toutefois d'une classification complexe, difficile à appliquer dans la pratique quotidienne (Tableau I).

En 2000, l'American College of Chest Physicians (ACCP) a proposé une classification plus simple [53], reposant à la fois sur les données de l'imagerie et de l'analyse du liquide pleural, permettant la stratification des EPP en quatre catégories en fonction du risque d'évolution défavorable (Tableau II).

Plus récemment, la British Thoracic Society (BTS) a proposé une classification [54] séparant les EPP en trois catégories : EPP simple, EPP compliqué et empyème. Cette classification reprend en grande partie les items de l'ACCP en y intégrant le taux de LDH. En revanche, elle n'inclut pas les données relatives au volume de l'épanchement (Tableau III).

En France, le collège des enseignants de Pneumologie [55] distingue les épanchements les épanchements parapneumoniques simples des épanchements parapneumoniques compliqués selon l'abondance de l'épanchement, son cloisonnement, l'aspect macroscopique, le pH et l'examen bactériologique. La glycopleurie et le taux de LDH ne sont pas mentionnés (Tableau IV).

- Prise en charge

- Antibiothérapie

L'antibiothérapie doit être débutée précocement, au mieux dès le stade de pneumopathie. Elle permet en effet d'éviter le développement d'un épanchement pleural en cas de pneumonie et 
prévient l'évolution vers la purulence en cas d'EPP [16]. Elle est par ailleurs suffisante pour la prise en charge des EPP non compliqués vus précocement, ne nécessitant pas d'évacuation pleurale [56].

L'antibiothérapie est initialement empirique. Elle doit à la fois tenir compte des germes habituellement rencontrés et avoir une bonne diffusion dans le liquide pleural infecté [1].

Les $\beta$-lactamines constituent les antibiotiques de référence pour le traitement des infections à pneumocoque et streptocoques du groupe milleri $[57,58]$. Leur bonne diffusion intrapleurale a été démontrée à partir de modèles animaux [59]. Ces molécules restent actives en milieu acide (purulent) mais sont inactivées par les germes sécréteurs de $\beta$-lactamase [60], fréquemment rencontrés dans les EPP compliqués (Staphylococcus aureus, Klebsiella pneumoniae, Haemophilus influenzae, germes anaérobies...). L'association amoxicilline-acide clavulanique constitue donc un bon choix antibiotique initial compte tenu de la bonne diffusion de l'acide clavulanique dans le liquide pleural [61].

Les autres options sont l'association d'une céphalosporine de troisième génération associée au métronidazole ou à la clindamycine, qui possèdent également une bonne diffusion pleurale [59].

L'utilisation d'aminosides n'est pas justifiée en raison de leur diffusion médiocre dans l'empyème expérimental et de leur inactivité en milieu acide [62]. Enfin, les nouvelles fluoroquinolones avec activité anti-pneumococcique (lévofloxacine, moxifloxacine) peuvent être utilisées en cas d'allergie aux $\beta$-lactamines mais des résistances ont été rapportées avec Bacteroides fragilis [1].

La voie intraveineuse est habituellement utilisée initialement. Le relais oral peut être effectué après résolution du sepsis [54]. La durée du traitement n'est pas codifiée, en l'absence d'essai randomisé, mais devrait être d'au moins 3 à 6 semaines $[1,18,54]$. L'antibiothérapie doit être réévaluée en fonction des résultats des prélèvements mais compte tenu de la difficulté d'identification des germes anaérobies, le maintien d'un inhibiteur des $\beta$-lactamases est recommandé [54]. À l'inverse, l'utilisation d'antibiotiques actifs contre les germes intracellulaires (Legionella et Mycoplasma pneumoniae principalement) n'est pas recommandée en première intention en raison de la rareté des EPP qui leurs sont attribués [13, 24, 54]. Il n'y a aucune étude ou recommandation validant l'utilisation d'une antibiothérapie à double dose dans cette pathologie.

En cas d'infection nosocomiale, le spectre de l'antibiothérapie initiale doit être élargi et comporter une activité contre les anaérobies, Pseudomonas aeruginosa et Staphylococcus aureus résistant à la méticilline [24,54,63].

Enfin, le recours aux antibiotiques intrapleuraux n'a pas montré son efficacité [12].

- L'antibiothérapie de référence repose sur l'association amoxicilline-acide clavulanique, notamment en l'absence de germe retrouvé.

- En cas d'allergie aux pénicillines, l'association céphalosporine de troisième génération et métronidazole peut être utilisée.

- La durée de l'antibiothérapie est de 3 à 6 semaines. 
- Traitement évacuateur

Une évacuation la plus complète du liquide pleural est nécessaire pour le contrôle de l'infection. Cette évacuation est rendue difficile par la viscosité du liquide et l'éventuelle existence de loculations.

Les principales options thérapeutiques sont représentées par les ponctions pleurales évacuatrices répétées, le drainage thoracique et la thoracoscopie de débridement.

La thoracoscopie médicale a été décrite dans le traitement des EPP, notamment en cas d'épanchements multiloculés. Néanmoins, il n’y a pas d'étude randomisée évaluant cette modalité thérapeutique $[64,65]$.

Un repérage échographique avant tout geste invasif pleural (ponction, drainage) est préconisé [66-68].

- $\quad$ Ponctions pleurales répétées (PPR)

Certains auteurs recommandent de "profiter" de la ponction pleurale diagnostique pour évacuer l'épanchement pleural [69, 70]. Quelques équipes préconisent la répétition des ponctions évacuatrices, éventuellement associées à la réalisation de lavages pleuraux [72, 73]. Un repérage échographique préalable est conseillé. [73, 74].

Réalisées de façon itérative, les PPR présentent l'avantage d'être peu invasives et permettent d'éviter les complications du drainage thoracique ou de la chirurgie (hémothorax, risque infectieux, complications postopératoires...). Elles permettent également une meilleure mobilité des patients, voire la gestion de certains malades en ambulatoire.

Chez l'homme, l'efficacité de cette technique a seulement été évaluée par des petites séries, le plus souvent rétrospectives, toutes antérieures à l'année 2000 et comportant parfois des PI d'étiologies diverses (Tableau V). Il n'existe aucune étude comparant les ponctions répétées au drainage thoracique chez l'adulte [63].

Les taux de succès sont très variables, allant de à $2,4 \%$ à $100 \%$, et la mortalité comprise entre 0 et $25 \%$ [72, 73]. L'efficacité de cette technique semble meilleure chez l'enfant [75].

Les principales complications des ponctions répétées sont la douleur, la toux, les réactions vasovagales et les pneumothorax iatrogènes. Le risque de saignement et d'œdème de réexpansion est plus rare [74]. Par ailleurs, cette stratégie thérapeutique peut nécessiter un nombre important de ponctions pleurales, à l'origine d'une durée d'hospitalisation plus longue : dans la série de Simmers et coll. [73], les patients avaient bénéficié de 7,7 ponctions en moyenne pour une durée moyenne d'hospitalisation de 31 jours.

Dans notre expérience personnelle, à propos de 79 patients traités par ponctions répétées, le nombre médian de ponctions était de 3 et la durée moyenne d'hospitalisation de 21 jours. Le pourcentage de recours à la chirurgie n'était que de $4 \%$. Le taux de pneumothorax iatrogène était de $6 \%$ mais aucun n'a nécessité de drainage thoracique [70].

- Drainage thoracique à thorax fermé

L'insertion d'un drain thoracique au sein du liquide pleural infecté constitue l'attitude classique du traitement évacuateur de première intention [76].

Les drains utilisés sont soit de gros calibre (24 à $36 \mathrm{~F})$, soit de petit calibre (8 à $24 \mathrm{~F})$. L'insertion 
du drain s'effectue par incision intercostale, par l'intermédiaire d'un trocart, ou selon la technique de Seldinger (drains de petit calibre) $[63,76,77]$.

La définition du succès du drainage thoracique n'est pas consensuelle mais la plus utilisée est représentée par la régression des signes cliniques et biologiques d'infection, associée à une réexpansion pulmonaire complète sans recours à un traitement chirurgical complémentaire $[42,76]$.

Drainage thoracique sans repérage ("à l'aveugle ”)

Classiquement, la mise en place d'un drain thoracique est effectuée au lit du malade, sous anesthésie locale, sans repérage radiologique préalable. L'utilisation de drains de gros calibre $(>28 \mathrm{~F})$, plus douloureux, ne semble pas préférable malgré la viscosité du liquide car leur supériorité par rapport aux drains de petit calibre n'a pas été démontrée $[18,22,78]$. De même, la supériorité de la mise en aspiration du drain par rapport au drainage passif n'a pas été mise en évidence [79].

Les taux de succès habituellement observés en l'absence de repérage radiologique sont inférieurs à $50 \%$, y compris en cas d'utilisation de drains de gros calibre [27].

\section{Drainage thoracique guidé par l'imagerie}

La mise en place de drains thoraciques peut également être guidée par l'échographie ou la tomodensitométrie $[80,81]$. Cette technique permet la mise en place de drains de plus petit calibre, directement au sein des poches pleurales délimitées par les cloisons de fibrine [82]. Les taux de succès sont supérieurs à ceux obtenus en l'absence de repérage radiologique et varient entre 70 et $94 \%$ [80, 83, 84], y compris en seconde intention après échec du drainage conventionnel $[84,85]$. La majorité de ces études préconisent la réalisation de rinçages au sérum physiologique afin de prévenir l'occlusion des drains et l'utilisation d'agents fibrinolytiques pour favoriser le drainage pleural. Les résultats sont inférieurs en cas d'empyèmes [83] et en présence de loculations [84].

L'utilisation de drains plus petits (10 à $14 \mathrm{~F})$ permet, tout en gardant la même efficacité, d'améliorer leur tolérance et de réduire le risque de complication [80, 81, 86, 87].

Dans l'étude MIST 2, les drains étaient de taille inférieure à 15F dans plus de $86 \%$ des cas [88].

\section{- $\quad$ Traitement chirurgical}

Le traitement chirurgical comporte la thoracoscopie de débridement (médicale et vidéothoracoscopie) et la chirurgie de décortication pleurale.

\section{Thoracoscopie de débridement}

La pleuroscopie médicale, réalisée par les pneumologues, a été développée dans les années 1910 pour le débridement des pleurésies tuberculeuses [89]. En dehors des patients fragiles présentant un haut risque chirurgical, cette technique a été abandonnée au profit de la vidéo-thoracoscopie (VATS) [78].

La VATS nécessite une anesthésie générale et une intubation sélective permettant la ventilation unipulmonaire. Elle permet d'évacuer les débris fibrinopurulents, d'effondrer les cloisonnements (débridement), de réaliser une toilette de la cavité pleurale et de mettre en place un ou plusieurs 
drains thoraciques sous contrôle de la vue $[1,90]$. Certaines équipes préconisent de recourir à une thoracotomie de conversion pour décortication pleurale en l'absence de ré-expansion pulmonaire peropératoire après débridement $[91,92]$. La VATS offre cependant la possibilité de réaliser un débridement pleural avec des taux de succès identiques à la chirurgie ouverte et une morbidité postopératoire plus faible [93].

Plusieurs études non contrôlées ont évalué les résultats de la prise en charge par VATS, le plus souvent après échec du drainage thoracique, avec des taux de succès compris entre 71 et $93 \%$ [9, 94, 95].

Seules deux études randomisées ont comparé le drainage médical avec la chirurgie par VATS. Wait et coll. [96], en 1997, ont randomisé 20 patients (11 patients traités par VATS en première intention, 9 patients traités par drainage thoracique avec instillation de streptokinase pendant 3 jours). La mortalité était identique dans les deux groupes. En revanche, les patients traités par chirurgie avaient un taux de succès plus important (10/11) que les patients traités médicalement (4/9) ainsi qu'une durée de drainage et une durée d'hospitalisation plus faibles. Tous les échecs du traitement médical ont été récupérés efficacement par VATS, sans aucun recours à la thoracotomie.

Bilgin et coll. [97] ont rapporté en 2006 une série de 70 patients traités par VATS $(n=35)$ ou drainage thoracique $(n=35)$. Le taux de succès, défini par l'absence de nécessité de thoracotomie pour décortication pleurale ultérieure, était de $83 \%$ dans le groupe VATS contre $63 \%$ dans le groupe drainage médical. La durée d'hospitalisation était significativement plus faible dans le groupe VATS.

Bien que randomisées, ces études comportaient plusieurs limites. Les drains médicaux étaient placés sans repérage préalable expliquant les faibles taux de succès du traitement médical (respectivement de $45 \%$ et de $63 \%$ ) par rapport aux données de la littérature. L'appréciation de l'échec était laissée à l'initiative des cliniciens. Enfin, le nombre de patients était limité.

\section{Chirurgie de décortication pleurale (Open decortication)}

La chirurgie de décortication est une intervention lourde, non réalisable en cas de comorbidités importantes, qui consiste en l'ablation de la pachypleurite viscérale pour permettre la réexpansion du poumon dans la cavité pleurale [42,98]. Elle repose sur la thoracotomie, éventuellement complétée par la réalisation d'une fenestration par résection costale (thoracostomie) permettant un drainage continu de la cavité pleurale [63]. La mortalité est comprise entre 3 et $10 \%$ [76].

Elle peut être réalisée précocement, le plus souvent en seconde intention, soit dans un but de contrôle du sepsis, soit après échec d'une autre technique (drainage ou thoracoscopie) [99]. Elle peut aussi être proposée en cas de contre-indication à la thoracoscopie [2]. Cependant, une revue de la littérature récente comparant la chirurgie par thoracotomie à la thoracoscopie (VATS) fait état de plus mauvais résultats postopératoires par rapport à la VATS, avec une durée d'hospitalisation plus longue, une augmentation de la douleur et du risque infectieux postopératoires et une mortalité à 30 jours plus importante [100]. La thoracotomie doit donc être évitée à la phase aiguë au profit de la chirurgie mini-invasive (VATS) qui semble offrir de meilleurs résultats.

La décortication pleurale peut également être proposée plus tardivement, à la phase organisée, en 
cas de syndrome restrictif symptomatique sévère dans un but de récupération fonctionnelle [2]. Un délai d'au moins 6 mois doit cependant être respecté du fait de la possibilité de résorption de la pachypleurite pariétale après une longue période d'évolution [18].

- Recommandations concernant le traitement évacuateur

\section{Recommandations de la BTS [54]}

Dans ses recommandations, la BTS préconise le recours au drainage thoracique en première intention en cas d'EPP compliqué et d'empyème. Les critères définis comme imposant le drainage thoracique sont les suivants :

- liquide pleural purulent ou trouble (grade B);

- examen bactériologique positif (examen direct ou culture) (grade B);

- $\mathrm{pH}$ pleural inférieur à 7,2 (grade $\mathrm{B})$;

- présence de loculations ou épanchement pleural abondant (grade C).

En cas de persistance du sepsis associé à une persistance de la collection pleurale malgré le drainage thoracique, la BTS recommande le recours à la chirurgie dans un délai de 5 à 7 jours.

\section{Recommandations de l'ACCP [53]}

Les recommandations de l'ACCP reposent sur une analyse de la littérature concernant les différents traitements évacuateurs de première intention (ponctions évacuatrices, drainage thoracique avec ou sans fibrinolyse, VATS et chirurgie ouverte). Les conclusions sont les suivantes :

- les EPP de catégorie 1 et 2 ne requièrent pas de traitement évacuateur (grade D) ;

- les EPP de catégorie 3 et 4 ne doivent pas être évacués par ponctions pleurales évacuatrices ou drainage thoracique sans fibrinolytiques (grade C) ;

- les EPP de catégorie 3 et 4 doivent être évacués soit par drainage thoracique avec fibrinolytiques, soit par VATS, soit par chirurgie ouverte (grade C).

L'ACCP positionne donc la chirurgie comme premier traitement évacuateur à mettre en œuvre en cas d'EPP compliqué, au même titre que le drainage thoracique avec fibrinolyse. Il s'agit du principal point de divergence par rapport aux recommandations de la BTS qui placent la chirurgie comme une option de seconde intention.

Les ponctions pleurales répétées ne sont préconisées, en première intention, ni par la BTS, ni par l'ACCP.

- Le traitement évacuateur de première intention repose soit sur la réalisation de ponctions pleurales répétées, soit sur le drainage thoracique, soit sur la chirurgie (VATS).

- Les ponctions pleurales et le drainage thoracique doivent être guidés par l'échographie pleurale.

- L'indication du traitement doit tenir compte des comorbidités, notamment lorsqu'une chirurgie est envisagée.

- La mise en place d'un drain thoracique repose sur l'utilisation de drains de petite taille $(<15 \mathrm{~F})$

- La chirurgie de décortication pleurale ne doit être envisagée qu'à distance en vue de 
réduire les séquelles restrictives.

- $\quad$ Place de la fibrinolyse intrapleurale

L'injection intrapleurale d'agents fibrinolytiques, utilisée pour la première fois en 1949 [101], a pour objectif d'améliorer l'efficacité du drainage en lysant les structures fibreuses responsables de loculations au cours de la phase d'enkystement [1]. La fibrinolyse intrapleurale peut être utilisée aussi bien lors des ponctions pleurales répétée que lors du drainage thoracique. En cas de PPR, l'agent fibrinolytique est laissé dans la cavité pleurale jusqu'à la ponction suivante. En cas de drain thoracique, l'agent fibrinolytique est injecté directement dans le drain qui est clampé pendant 2 heures. Les agents fibrinolytiques utilisés sont la streptokinase, l'urokinase et le tissueplasminogen activator (t-PA). Ces enzymes sont de puissants activateurs du plasminogène, conduisant à la formation de plasmine qui dégrade la fibrine, le fibrinogène et d'autres molécules apparentées [102]. La durée de vie intrapleurale de $45 \mathrm{~min}$ plaide en faveur d'une utilisation pluriquotidienne.

Plusieurs études contrôlées randomisées ont comparé le drainage associé à la fibrinolyse intrapleurale au drainage seul. Ces études ont montré un bénéfice de la fibrinolyse intrapleurale, cette dernière permettant une amélioration de la quantité totale de liquide pleural drainé [103, 104], une diminution du recours à la chirurgie [104-106], une réduction de la durée de la fièvre et de la durée d'hospitalisation [104] et une meilleure régression des anomalies radiologiques [106]. Elles n'ont pas retrouvé en revanche d'effet sur la mortalité.

En 2005, la publication de l'essai MIST-1 (Multicenter Intrapleural Sepsis Trial) évaluant l'utilisation de streptokinase contre placebo est l'essai le plus important avec un total de 430 patients [22], alors que les études précédentes concernaient de petits effectifs. Les résultats ne montraient pas de différence en termes de recours à la chirurgie (Figure 10), de durée d'hospitalisation ou d'amélioration radiologique et confirmaient l'absence d'impact du traitement fibrinolytique sur la mortalité. De plus, les effets secondaires (douleur thoracique, fièvre, allergie) étaient davantage observés dans le groupe streptokinase avec une tendance non significative $(\mathrm{p}=0,08)$. Il est à noter toutefois que le drainage n'était pas guidé par l'imagerie, que les drains utilisés étaient de petit calibre ( $12 \mathrm{~F}$ en moyenne) et que la décision de recours au traitement chirurgical était laissée à l'appréciation des praticiens. Par ailleurs, une fibrinolyse intrapleurale avait été administrée quel que soit le stade et le bénéfice de la fibrinolyse n'avait pas été évalué spécifiquement dans le sous-groupe de patients présentant un épanchement cloisonné.

Ces résultats, en défaveur de la fibrinolyse intrapleurale, ont été confirmés par deux métaanalyses $[107,108]$ ne retrouvant pas de réduction significative de la mortalité ou du recours à la chirurgie en cas de fibrinolyse intrapleurale.

Les effets secondaires systémiques des fibrinolytiques sont exceptionnels, y compris avec la streptokinase [109]. Il n'y a pas de modification des paramètres de coagulation ou de fibrinolyse systémique [110] ni d'augmentation du risque d'hémorragie intrapleurale [22]. L'effet secondaire le plus fréquent est l'apparition d'une réaction fébrile [18]. Des réactions allergiques sont également possibles, aussi bien avec la streptokinase que l'urokinase [109]. Enfin l'utilisation de streptokinase induit la synthèse d'anticorps anti-streptokinase susceptibles de réduire l'efficacité de la streptokinase en cas d'injection systémique ultérieure [22]. 
Les agents fibrinolytiques n'ont aucun effet sur la réduction de la viscosité du pus qui est principalement attribuable à l'accumulation de débris cellulaires et d'ADN bactérien (aboutissant à la formation de biofilm). L'adjonction de désoxyribonucléase recombinante (DNase) permettant la dépolymérisation de l'ADN bactérien a donc été proposée par certains auteurs qui rapportent une amélioration du drainage pleural suite à l'utilisation de DNase [111, 112].

Ces données préliminaires ont été confirmées en 2011 par l'étude MIST-2 [88] qui regroupait 210 patients randomisés en quatre groupes : t-PA seul, DNase seule, t-PA associé à la DNase et double placebo. Le drainage comportait la mise en place de drains de petite taille $(<15 \mathrm{~F})$ dans plus de $80 \%$ des cas. Les résultats mettaient en évidence une réduction plus importante du volume de l'épanchement pleural sur la radiographie thoracique, une diminution de la fièvre et de l'hyperleucocytose au $7^{\mathrm{e}}$ jour, une diminution de la durée d'hospitalisation et une diminution du recours à la chirurgie uniquement chez les patients traités par l'association t-PA et DNase (Figure 11), sans effet sur la mortalité. En revanche, ces bénéfices n'étaient pas retrouvés dans les groupes t-PA et DNase seuls, confirmant ainsi les résultats de l'étude MIST-1 [22]. Enfin, il n'y avait pas de différence concernant la survenue d'effets indésirables entre les groupes. Il semble donc que l'association t-PA et DNase présente un intérêt dans la prise en charge des EPP compliqués, mais ceci ne figure pas encore dans les recommandations et nécessite des études complémentaires de confirmation.

- La fibrinolyse intrapleurale n'a pas fait la preuve de son efficacité lorsqu'elle est utilisée seule.

- En association avec la DNAse, la fibrinolyse pourrait permettre un meilleur drainage de l'épanchement pleural, une réduction de la durée d'hospitalisation et une réduction du recours à la chirurgie sans impact sur la mortalité.

- Les effets secondaires de la fibrinolyse intrapleurale sont exceptionnels.

- Kinésithérapie respiratoire

Bien que non recommandée par la BTS et l'ACCP, la kinésithérapie pleurale est largement réalisée en pratique en France et est recommandée dans les manuels de pneumologie pour les étudiants en médecine [55]. Elle a pour but de réduire les séquelles fonctionnelles et doit donc être pratiquée de façon prolongée [18]. Le collège des universitaires de maladies infectieuses et tropicales recommande la réalisation d'une kinésithérapie respiratoire pendant 3 à 6 mois [113]. Cependant, il n'existe pas d'étude randomisée évaluant l'efficacité de la kinésithérapie respiratoire dans cette pathologie.

\section{- Pronostic}

La morbidité et la mortalité des pneumopathies infectieuses sont augmentées lorsqu'un EPP est mis en évidence, cette situation correspondant en fait à un retard de prise en charge de la pneumopathie initiale [9]. Par ailleurs, le risque d'échec du traitement d'une pneumonie communautaire est multiplié par 2,7 en cas d'EPP [114].

La mortalité en cas d'empyème est estimée entre 5 et $30 \%[19,115]$. Dans une étude prospective portant sur 85 patients atteints de pleurésie parapneumonique, la mortalité hospitalière était de $4,7 \%$ alors que la mortalité globale (incluant un suivi de 400 jours après drainage thoracique) 
s'élevait à $14 \%$ [115].

Un retard à l'initiation de l'évacuation pleurale est responsable d'une augmentation de la mortalité [116].

La mortalité est par ailleurs directement influencée par les comorbidités sous-jacentes et peut atteindre jusqu'à $40 \%$ en cas d'immunosuppression [9]. Les autres facteurs de mauvais pronostic identifiés sont un âge élevé, la dénutrition, l'hypo-albuminémie, le diabète, les maladies néoplasiques et les cardiopathies $[19,115,116]$.

La mortalité varie également en fonction de l'étiologie microbienne. L'analyse des données bactériologiques de l'étude MIST-1 [24] fait apparaitre une mortalité plus élevée pour les infections à bacilles à Gram négatif, à staphylocoque doré ou polymicrobiennes à germes aérobies. À l'inverse, les infections à streptocoque et à anaérobies ont un meilleur pronostic.

Cette différence avait déjà été rapportée par Jerng [58] qui retrouvait un meilleur pronostic en cas d'infection à Streptococcus milleri et par Chen [20] qui avait mis en évidence un pronostic plus sombre en cas d'infection à bacilles à Gram négatif qui seraient également plus fréquemment retrouvés chez les patients porteurs de comorbidités.

Les séquelles pleurales à long terme des EPP sont principalement représentées par l'apparition* d'une pachypleurite qui est mise en évidence chez plus de $13 \%$ des patients [117]. 


\section{CONCLUSION}

Les épanchements parapneumoniques représentent un problème épidémiologique croissant imposant leur diagnostic à un stade précoce compte tenu du mauvais pronostic en l'absence de traitement.

L'antibiothérapie doit être instaurée rapidement et être active sur les germes anaérobies. Les posologies et la durée des traitements sont mal codifiées.

Le traitement évacuateur doit lui aussi être précoce. Cependant, ses modalités restent controversées. Les recommandations internationales préconisent le recours au drainage thoracique ou à la chirurgie en première intention mais le niveau de preuve de ces recommandations reste faible. Quelques études suggèrent la possibilité de réaliser des ponctions pleurales évacuatrices répétées.

La fibrinolyse intrapleurale seule n'a pas fait la preuve de son efficacité. En revanche lorsqu'elle est associée à l'administration de DNase, il semble qu'elle améliore le pronostic. 


\section{Points forts}

- Les épanchements parapneumoniques représentent l'étiologie la plus importante des pleurésies infectieuses, avec une incidence en augmentation.

- La mortalité attribuable aux épanchements parapneumoniques est élevée.

- Les germes les plus fréquemment rencontrés sont les streptocoques du groupe milleri et les bacilles à Gram négatif.

- La ponction pleurale exploratrice doit être réalisée précocement. Elle permet de classer les EPP en plusieurs stades de sévérité croissante (Cf tableaux 1,2,3,4).

- Les critères permettant de définir les épanchements parapneumoniques compliqués sont l'aspect macroscopique purulent, le dosage du $\mathrm{pH}$ pleural inférieur à 7.2, la positivité de l'examen direct ou de la culture bactérienne ou la présence de loculations.

- Seuls les épanchements parapneumoniques compliqués doivent être évacués. L'antibiothérapie doit être précoce et comporter une activité anti-anaérobies, sauf en cas de pleurésie à pneumocoque. L'antibiothérapie de référence est l'association amoxicilline-acide clavulanique.

- Les modalités du traitement évacuateur sont débattues et reposent soit sur la réalisation de ponctions pleurales évacuatrices répétées, soit sur le drainage thoracique, soit sur la chirurgie (VATS).

- Un repérage échographique est recommandé avant réalisation des ponctions pleurales répétées ou insertion d'un drain thoracique

- La taille des drains thoraciques utilisés doit être inférieure à 15 french.

- Deux grands essais ont retrouvé une absence de rôle bénéfique de la fibrinolyse intrapleurale, sauf lorsqu'elle est associée à l'adjonction de DNase intrapleurale.

Questions

A Répondre par vrai ou faux

1. L'épidémiologie microbienne est identique entre les épanchements pleuraux parapneumoniques et les pneumonies.

2. Les pleurésies infectieuses (PI) sont en majorité d'origine pulmonaire.

3. L'incidence des épanchements pleuraux parapneumoniques (EPP) et des empyèmes a diminué au cours des deux dernières décennies.

4. De 5 à $10 \%$ des EPP correspondent à des empyèmes.

5. Dans plus de deux tiers des cas d'EPP, on retrouve une comorbidité sous-jacente, souvent responsable d'une pneumopathie d'inhalation.

6. En pratique, les PI sont rarement associées à une immunodépression.

7. Les bactéries à Gram négatif et les germes anaérobies sont de nos jours plus souvent en cause que les pneumocoques dans les EPP.

8. Les pneumopathies d'inhalation sont plus volontiers responsables d'infections polymicrobiennes et à germes anaérobies.

9. Les EPP compliquant une légionellose sont rares mais se compliquent fréquemment d'empyème. 
10. Les épanchements secondaires à des pneumopathies à bacilles à Gram négatif et à germes anaérobies sont purulents dans $90 \%$ des cas.

11. Le principal germe en cause en cas d'infection nosocomiale est Staphylococcus aureus.

12. La culture pleurale est négative dans environ $40 \%$ des cas.

13. Le premier stade d'un épanchement est exsudatif et lié à une augmentation de la perméabilité capillaire et il est initialement stérile.

14. Dès le stade exsudatif, un épanchement active la cascade de la coagulation et inhibe l'activité fibrinolytique.

15. On peut distinguer cliniquement un EPP compliqué d'un EPP non compliqué par l'existence d'une fièvre et d'une altération de l'état général.

16. La ponction pleurale exploratrice, étape essentielle dans le diagnostic des EPP, doit être précoce.

17. Les hémocultures ne retrouvent le germe responsable que dans $10 \%$ des cas.

18. Les épanchements parapneumoniques sont des transsudats.

19. Sur le plan cellulaire, une prédominance lymphocytaire dans le liquide pleural est en défaveur d'une étiologie bactérienne.

20. Dans le liquide de ponction pleurale, il faut doser la LDH, le pH et la glycopleurie pour détecter les épanchements compliqués.

21. Une antibiothérapie précoce, au stade de pneumopathie, permet d'éviter l'installation d'un épanchement pleural en cas de pneumonie et sa surinfection.

22. Les antibiotiques de référence pour le traitement des infections à pneumocoque et streptocoques du groupe milleri sont les $\beta$-lactamines, éventuellement associées à l'acide clavulanique, puis les aminosides en cas d'allergie.

23. Le contrôle de l'infection impose une évacuation la plus complète possible du liquide pleural par ponctions pleurales répétées ou, plus classiquement, par drainage thoracique à thorax fermé.

24. Le guidage échographique ou tomodensitométrique améliore le taux de succès des drainages thoraciques.

25. Le traitement évacuateur des EPP compliqués doit être chirurgical.

26. En général, la fibrinolyse intrapleurale ne permet pas d'augmenter le volume d'évacuation de l'épanchement.

27. Les agents fibrinolytiques, en diminuant la viscosité du pus, facilitent l'évacuation pleurale.

28. La mortalité de l'empyème est estimée entre 5 et $30 \%$ et peut atteindre $40 \%$ en cas d'immunosuppression.

\section{Réponses}

A Vrai ou faux

1.Faux, 2.vrai, 3.faux, 4.vrai, 5.vrai, 6.faux, 7.vrai, 8.vrai, 9.faux, 10.vrai, 11.vrai, 12.vrai, 13.vrai, 14.faux, 15.faux, 16.vrai, 17.vrai, 18.faux, 19.vrai, 20.vrai, 21.vrai, 22.faux, 23.vrai, 24.vrai, 25.faux, 25.faux, 25.faux, 26.vrai

\section{Remerciements :}

Jean-Sébastien Poineuf pour le premier travail rennais sur les épanchements parapneumoniques compliqués. 


\section{- REFERENCES}

[1] Foulon G, Debray MP, Crestani B. Pleurésies purulentes. Dans : Aubier M, Crestani B, Fournier M, Mal H. Traité de pneumologie. 2e éd. Medecine-Sciences Flammarion; 2009. p.415-20.

[2] Hamm H, Light RW. Parapneumonic effusion and empyema. European Respiratory Journal 1997;10:1150-6.

[3] Snider GL, Saleh SS. Empyema of the Thorax in Adults: Review of 105 Cases. Chest 1968;54:410-5.

[4] Strange C, Sahn SA. The definitions and epidemiology of pleural space infection. Semin Respir Infect 1999;14:3-8.

[5] Ashbaugh D. Empyema thoracis. Factors influencing morbidity and mortality. Chest 1991;99:1162-5.

[6] Alfageme I, Muñoz F, Peña N, Umbría S. Empyema of the thorax in adults. Etiology, microbiologic findings, and management. Chest 1993;103:839-43.

[7] Farjah F, Symons RG, Krishnadasan B, Wood DE, Flum DR. Management of pleural space infections: a population-based analysis. J Thorac Cardiovasc Surg 2007;133:346-51.

[8] Finley C, Clifton J, FitzGerald JM, Yee J. Empyema: an increasing concern in Canada. Canadian Respiratory Journal: Journal of the Canadian Thoracic Society 2008;15:85.

[9] Sahn SA. Diagnosis and Management of Parapneumonic Effusions and Empyema. Clinical Infectious Diseases 2007;45:1480-6.

[10] Light RW, Girard WM, Jenkinson SG, George RB. Parapneumonic effusions. The American Journal of Medicine 1980;69:507-12.

[11] Bartlett JG, Finegold SM. Anaerobic infections of the lung and pleural space. Am Rev Respir Dis 1974;110:56-77.

[12] Heffner JE, McDonald J, Barbieri C, Klein J. Management of parapneumonic effusions. An analysis of physician practice patterns. Arch Surg 1995;130:433-8.

[13] Fine NL, Smith LR, Sheedy PF. Frequency of pleural effusions in mycoplasma and viral pneumonias. N Engl J Med 1970;283:790-3.

[14] Miller JR JI. Post surgical Empyema. In: Shields TW, Locicero III J, Ponn KP eds. General thoracic surgery. Philadelphia : Lippincott Williams and Wilkins; 2000. p. 709-715

[15] Ahmed RA, Marrie TJ, Huang JQ. Thoracic Empyema in Patients with CommunityAcquired Pneumonia. The American Journal of Medicine 2006;119:877-83.

[16] Sahn SA. Management of complicated parapneumonic effusions. Am Rev Respir Dis 1993;148:813-7.

[17] Chapman SJ, Davies RJO. Recent advances in parapneumonic effusion and empyema. Curr Opin Pulm Med 2004;10:299-304.

[18] Riquet $M$, Badia A. Pleurésies purulentes aiguës à germes banals. Encycl Méd Chir (Editions Scientifiques et Médicales Elsevier SAS, Paris, tous droits réservés), Pneumologie,6-041-A-40, 2003, 13 p.

[19] Ferguson AD, Prescott RJ, Selkon JB, Watson D, Swinburn CR. The clinical course and management of thoracic empyema. QJM 1996;89:285-9.

[20] Chen K-Y. A 10-Year Experience With Bacteriology of Acute Thoracic Empyema : Emphasis 
on Klebsiella pneumoniae in Patients With Diabetes Mellitus. Chest 2000;117:1685-9.

[21] Huang H-C. Predicting Factors for Outcome of Tube Thoracostomy in Complicated Parapneumonic Effusion or Empyema. Chest 1999;115:751-6.

[22] Maskell NA, Davies CWH, Nunn AJ, Hedley EL, Gleeson FV, Miller R et al. UK controlled trial of intrapleural streptokinase for pleural infection. New England Journal of Medicine 2005;352:865-74.

[23] Voiriot G, Dury S, Parrot A, Mayaud C, Fartoukh M. Nonsteroidal antiinflammatory drugs may affect the presentation and course of community-acquired pneumonia. Chest 2011;139:387-94.

[24] Maskell NA. The Bacteriology of Pleural Infection by Genetic and Standard Methods and Its Mortality Significance. American Journal of Respiratory and Critical Care Medicine 2006;174:817-23.

[25] Whiley RA, Beighton D, Winstanley TG, Fraser HY, Hardie JM. Streptococcus intermedius, Streptococcus constellatus, and Streptococcus anginosus (the Streptococcus milleri group): association with different body sites and clinical infections. J Clin Microbiol 1992;30:243-4.

[26] Hage CA, abdul-Mohammed K, Antony VB. Pathogenesis of pleural infection. Respirology 2004;9:12-5.

[27] Lee-Chiong TL Jr, Matthay RA. Current diagnostic methods and medical management of thoracic empyemas. Chest Surg Clin N Am 1996;6:419-38.

[28] Rahman NM, Chapman SJ, Davies RJO. The approach to the patient with a parapneumonic effusion. Clin Chest Med 2006;27:253-66.

[29] Bartlett JG. Anaerobic bacterial infections of the lung and pleural space. Clin Infect Dis 1993;16 Suppl 4:S248-255.

[30] Heffner JE. Diagnosis and management of thoracic empyemas. Curr Opin Pulm Med 1996;2:198-205.

[31] Lin Y-C, Chen H-J, Liu Y-H, Shih C-M, Hsu W-H, Tu C-Y. A 30-month experience of thoracic empyema in a tertiary hospital: emphasis on differing bacteriology and outcome between the medical intensive care unit (MICU) and medical ward. South Med J 2008;101:484-9.

[32] Brook I, Frazier EH. Aerobic and anaerobic microbiology of empyema. A retrospective review in two military hospitals. Chest 1993;103:1502-7.

[33] Alkrinawi S, Chernick V. Pleural infection in children. Semin Respir Infect 1996;11:148-54.

[34] Kroboth FJ, Yu VL, Reddy SC, Yu AC. Clinicoradiographic correlation with the extent of Legionnaire disease. AJR Am J Roentgenol 1983;141:263-8.

[35] Randolph KA, Beekman JF. Legionnaires' disease presenting with empyema. Chest 1979;75:404-6.

[36] Light RW. A New Classification of Parapneumonic Effusions and Empyema. Chest 1995;108:299-301.

[37] Taryle DA, Potts DE, Sahn SA. The incidence and clinical correlates of parapneumonic effusions in pneumococcal pneumonia. Chest 1978;74:170-3.

[38] McLaughlin Krasna MJ. Parapneumonic empyema. In: Shields TW, Locicero III J, Ponn KP eds. General thoracic surgery. Philadelphia : Lippincott Williams and Wilkins; 2000. p. 699-708.

[39] Ko SC, Chen KY, Hsueh PR, Luh KT, Yang PC. Fungal empyema thoracis: an emerging clinical entity. Chest 2000;117:1672-8. 
[40] Insa R, Marín M, Martín A, Martín-Rabadán P, Alcalá L, Cercenado E, et al. Systematic use of universal 16S rRNA gene polymerase chain reaction (PCR) and sequencing for processing pleural effusions improves conventional culture techniques. Medicine (Baltimore) 2012;91:103-10.

[41] Saglani S, Harris KA, Wallis C, Hartley JC. Empyema: the use of broad range 16S rDNA PCR for pathogen detection. Arch Dis Child 2005;90:70-3.

[42] Light RW. Parapneumonic Effusions and Empyema. Proceedings of the American Thoracic Society 2006;3:75-80.

[43] Alemán C, Alegre J, Monasterio J, Segura RM, Armadans L, Anglés A, et al. Association between inflammatory mediators and the fibrinolysis system in infectious pleural effusions. Clin Sci 2003;105:601-7.

[44] Sahn SA, Reller LB, Taryle DA, Antony VB, Good JT Jr. The contribution of leukocytes and bacteria to the low pH of empyema fluid. Am Rev Respir Dis 1983;128:811-5.

[45] Lindstrom ST, Kolbe J. Community acquired parapneumonic thoracic empyema: predictors of outcome. Respirology 1999;4:173-9.

[46] Menzies SM, Rahman NM, Wrightson JM, Davies HE, Shorten R, Gillespie SH, et al. Blood culture bottle culture of pleural fluid in pleural infection. Thorax 2011;66:658-62.

[47] Heffner JE, Brown LK, Barbieri C, DeLeo JM. Pleural fluid chemical analysis in parapneumonic effusions. A meta-analysis. American Journal of Respiratory and Critical Care Medicine 1995;151:1700-8.

[48] Light RW, MacGregor MI, Ball WC Jr, Luchsinger PC. Diagnostic significance of pleural fluid $\mathrm{pH}$ and PCO2. Chest 1973;64:591-6.

[49] Pine JR, Hollman JL. Elevated pleural fluid pH in Proteus mirabilis empyema. Chest 1983;84:109-11.

[50] Potts DE, Taryle DA, Sahn SA. The glucose-pH relationship in parapneumonic effusions. Arch Intern Med 1978;138:1378-80.

[51] Maskell NA. Diagnostically Significant Variations in Pleural Fluid pH in Loculated Parapneumonic Effusions. Chest 2004;126:2022-4.

[52] Rahman NM, Mishra EK, Davies HE, Davies RJ, Lee YC. Clinically important factors influencing the diagnostic measurement of pleural fluid $\mathrm{pH}$ and glucose. Am J Respir Crit Care Med. 2008 Sep 1;178(5):483-90

[53] Colice GL. Medical and Surgical Treatment of Parapneumonic Effusions : An EvidenceBased Guideline. Chest 2000;118:1158-71.

[54] Davies HE, Davies RJO, Davies CWH, on behalf of the BTS Pleural Disease Guideline Group. Management of pleural infection in adults: British Thoracic Society pleural disease guideline 2010. Thorax 2010;65:ii41-ii53.

[55] Collège des Enseignants de Pneumologie. Référentiel National de Pneumologie (2ème édition). S Editions 2013.

[56] Berger HA, Morganroth ML. Immediate drainage is not required for all patients with complicated parapneumonic effusions. Chest 1990;97:731-5.

[57] Minton EJ, Macfarlane JT. Antibiotic resistant Streptococcus pneumoniae. Thorax 1996;51:S45-S50.

[58] Jerng JS, Hsueh PR, Teng L, Lee LN, Yang PC, Luh KT. Empyema thoracis and lung abscess caused by viridans streptococci. Am J Respir Crit Care Med 1997;156:1508-14. 
[59] Teixeira LR, Sasse SA, Villarino MA, Nguyen T, Mulligan ME, Light RW. Antibiotic levels in empyemic pleural fluid. Chest 2000;117:1734-9.

[60] Bryant RE, Rashad AL, Mazza JA, Hammond D. beta-Lactamase activity in human pus. J Infect Dis 1980;142:594-601.

[61] Boon RJ, Beale AS, Comber KR, Pierce CV, Sutherland R. Distribution of amoxicillin and clavulanic acid in infected animals and efficacy against experimental infections. Antimicrob Agents Chemother 1982;22:369-75.

[62] Shohet I, Yellin A, Meyerovitch J, Rubinstein E. Pharmacokinetics and therapeutic efficacy of gentamicin in an experimental pleural empyema rabbit model. Antimicrob Agents Chemother 1987;31:982-5.

[63] Girdhar A, Shujaat A, Bajwa A. Management of Infectious Processes of the Pleural Space: A Review. Pulmonary Medicine 2012;2012:1-10.

[64] Medford AR. Medical thoracoscopy in multiloculated and organised empyema. Respiration. 2013;85(1):87.

[65] Ravaglia C, Gurioli C, Tomassetti S, Casoni GL, Romagnoli M, Gurioli C, Agnoletti V, Poletti $\underline{\mathrm{V}}$. Is medical thoracoscopy efficient in the management of multiloculated and organized thoracic empyema?. Respiration. 2012;84(3):219-24

[66] Gordon CE, Feller-Kopman D, Balk EM, Smetana GW. Pneumothorax following thoracentesis: a systematic review and meta-analysis. Arch Intern Med. 2010 Feb 22;170(4):332-9.

[67] Diacon $\mathrm{AH}$, Brutsche $\mathrm{MH}$, Solèr M.Accuracy of pleural puncture sites: a prospective comparison of clinical examination with ultrasound. Chest. 2003 Feb;123(2):436-41.

[68] Havelock T, Teoh R, Laws D, Gleeson F; BTS Pleural Disease Guideline Group. Pleural procedures and thoracic ultrasound: British Thoracic Society Pleural Disease Guideline 2010. Thorax. 2010 Aug;65 Suppl 2:ii61-76.

[69] Light RW, Rodriguez RM. Management of parapneumonic effusions. Clin Chest Med 1998;19:373-82.

[70] Letheulle J, Tattevin P, Saunders L, Kerjouan M, Hervé Lena. Iterative Thoracentesis as First-Line Treatment of Complicated Parapneumonic Effusion. Plos One 2014; 9: e84788 1-7.

[71] Sasse S. The Utility of Daily Therapeutic Thoracentesis for the Treatment of Early Empyema*. Chest 1999;116:1703-8.

[72] Storm HK, Krasnik M, Bang K, Frimodt-Møller N. Treatment of pleural empyema secondary to pneumonia: thoracocentesis regimen versus tube drainage. Thorax 1992;47:821-4.

[73] Simmers TA, Jie C, Sie B. Minimally invasive treatment of thoracic empyema. Thorac Cardiovasc Surg 1999;47:77-81.

[74] Jones PW. Ultrasound-Guided Thoracentesis: Is It a Safer Method? Chest 2003;123:41823.

[75] Shoseyov D. Short-term Course and Outcome of Treatments of Pleural Empyema in Pediatric Patients: Repeated Ultrasound-Guided Needle Thoracocentesis vs Chest Tube Drainage. Chest 2002;121:836-40.

[76] Heffner JE, Klein JS, Hampson C. Interventional Management of Pleural Infections. Chest 2009;136:1148-59. 
[77] Koegelenberg CFN, Diaconi AH, Bolligeri CT. Parapneumonic Pleural Effusion and Empyema. Respiration 2008;75:241-50.

[78] Tassi GF, Davies RJO, Noppen M. Advanced techniques in medical thoracoscopy. European Respiratory Journal 2006;28:1051-9.

[79] Munnell ER. Thoracic drainage. Ann Thorac Surg 1997;63:1497-502.

[80] Moulton JS, Benkert RE, Weisiger KH, Chambers JA. Treatment of complicated pleural fluid collections with image-guided drainage and intracavitary urokinase. Chest 1995;108:1252-9.

[81] Klein JS, Schultz S, Heffner JE. Interventional radiology of the chest: image-guided percutaneous drainage of pleural effusions, lung abscess, and pneumothorax. American Journal of Roentgenology 1995;164:581-8.

[82] Moulton JS. Image-guided drainage techniques. Semin Respir Infect 1999;14:59-72.

[83] Keeling AN, Leong S, Logan PM, Lee MJ. Empyema and effusion: outcome of imageguided small-bore catheter drainage. Cardiovasc Intervent Radiol 2008;31:135-41.

[84] Shankar S, Gulati M, Kang M, Gupta S, Suri S. Image-guided percutaneous drainage of thoracic empyema: can sonography predict the outcome? Eur Radiol 2000;10:495-9.

[85] VanSonnenberg E, Nakamoto SK, Mueller PR, Casola G, Neff CC, Friedman PJ, et al. CTand ultrasound-guided catheter drainage of empyemas after chest-tube failure. Radiology 1984;151:349-53.

[86] Silverman SG, Mueller PR, Saini S, Hahn PF, Simeone JF, Forman BH, et al. Thoracic empyema: management with image-guided catheter drainage. Radiology 1988;169:5-9.

[87] Ulmer JL, Choplin RH, Reed JC. Image-guided catheter drainage of the infected pleural space. J Thorac Imaging 1991;6:65-73.

[88] Rahman NM, Maskell NA, West A, Teoh R, Arnold A, Mackinlay C, et al. Intrapleural use of tissue plasminogen activator and DNase in pleural infection. New England Journal of Medicine 2011;365:518-26.

[89] Loddenkemper R. Thoracoscopy--state of the art. Eur Respir J. 1998 Jan;11(1):213-21.

[90] Ridley PD, Braimbridge MV. Thoracoscopic debridement and pleural irrigation in the management of empyema thoracis. Ann Thorac Surg 1991;51:461-4.

[91] Landreneau RJ, Keenan RJ, Hazelrigg SR, Mack MJ, Naunheim KS. Thoracoscopy for empyema and hemothorax. Chest 1996;109:18-24.

[92] Roberts JR. Minimally invasive surgery in the treatment of empyema: intraoperative decision making. Ann Thorac Surg 2003;76:225-230; discussion 229-230.

[93] Zahid I, Nagendran M, Routledge T, Scarci M. Comparison of video-assisted thoracoscopic surgery and open surgery in the management of primary empyema. Curr Opin Pulm Med 2011;17:255-9.

[94] Lawrence DR, Ohri SK, Moxon RE, Townsend ER, Fountain SW. Thoracoscopic debridement of empyema thoracis. Ann Thorac Surg 1997;64:1448-50.

[95] Luh S-P, Chou M-C, Wang L-S, Chen J-Y, Tsai T-P. Video-assisted thoracoscopic surgery in the treatment of complicated parapneumonic effusions or empyemas: outcome of 234 patients. Chest 2005;127:1427-32.

[96] Wait MA, Sharma S, Hohn J, Nogare AD. A Randomized Trial of Empyema Therapy. Chest 1997;111:1548-51.

[97] Bilgin $M$, Akcali $Y$, Oguzkaya F. Benefits of early aggressive management of empyema 
thoracis. ANZ J Surg 2006;76:120-2.

[98] Thurer RJ. Decortication in thoracic empyema. Indications and surgical technique. Chest Surg Clin N Am 1996;6:461-90.

[99] Pothula V, Krellenstein DJ. Early aggressive surgical management of parapneumonic empyemas. Chest 1994;105:832-6.

[100] Chambers A, Routledge T, Dunning J, Scarci M. Is video-assisted thoracoscopic surgical decortication superior to open surgery in the management of adults with primary empyema? Interact Cardiovasc Thorac Surg 2010;11:171-7.

[101] Tillett WS, Sherry S. The effect in patients of streptococcal fibrinolysin (streptokinase) and streptococcal desoxyribonuclease on fibrinous, purulent, and sanguinous pleural exudations. Journal of Clinical Investigation 1949;28:173.

[102] Bouros D, Schiza S, Siafakas N. Utility of fibrinolytic agents for draining intrapleural infections. Semin Respir Infect 1999;14:39-47.

[103] Bouros D, Schiza S, Tzanakis N, Chalkiadakis G, Drositis J, Siafakas N. Intrapleural Urokinase versus Normal Saline in the Treatment of Complicated Parapneumonic Effusions and Empyema A Randomized, Double-Blind Study. American Journal of Respiratory and Critical Care Medicine 1999;159:37-42.

[104] Tuncozgur B, Ustunsoy H, Sivrikoz MC, Dikensoy O, Topal M, Sanli M, et al. Intrapleural urokinase in the management of parapneumonic empyema: a randomised controlled trial. Int J Clin Pract 2001;55:658-60.

[105] Diacon AH. Intrapleural Streptokinase for Empyema and Complicated Parapneumonic Effusions. American Journal of Respiratory and Critical Care Medicine 2004;170:49-53.

[106] Davies RJ, Traill ZC, Gleeson FV. Randomised controlled trial of intrapleural streptokinase in community acquired pleural infection. Thorax 1997;52:416-21.

[107] Tokuda Y. Intrapleural Fibrinolytic Agents for Empyema and Complicated Parapneumonic Effusions: A Meta-analysis. Chest 2006;129:783-90.

[108] Cameron R, Davies HR. Intra-pleural fibrinolytic therapy versus conservative management in the treatment of adult parapneumonic effusions and empyema. Cochrane Database Syst Rev 2008;2.

[109] Sahn SA. Use of fibrinolytic agents in the management of complicated parapneumonic effusions and empyemas. Thorax 1998;53 Suppl 2:S65-72.

[110] Davies C, Lok S, Davies R. The systemic fibrinolytic activity of intrapleural streptokinase. American Journal of Respiratory and Critical Care Medicine 1998;157:328-30.

[111] Simpson G, Roomes D, Reeves B. Successful treatment of empyema thoracis with human recombinant deoxyribonuclease. Thorax 2003;58:365-6.

[112] Fujiwara K, Yasumitsu T, Nakagawa K, Shiono S, Fukuhara K. Intrapleural streptokinasestreptodornase in the treatment of empyema and hemothorax. Kyobu Geka 2002;55:1115-9.

[113] E.PILLY Maladies infectieuses et tropicales 2012. Collège des universitaires de Maladies Infectieuses et Tropicales (CMIT ). 23e éd. Vivactis plus; 2012

[114] Menéndez R, Torres A, Zalacaín R, Aspa J, Martín Villasclaras JJ, Borderías L, et al. Risk factors of treatment failure in community acquired pneumonia: implications for disease outcome. Thorax 2004;59:960-5.

[115] Davies CWH, Kearney SE, Gleeson FV, Davies RJO. Predictors of outcome and long-term 
survival in patients with pleural infection. American Journal of Respiratory and Critical Care Medicine 1999;160:1682-7.

[116] Cham CW, Haq SM, Rahamim J. Empyema thoracis: a problem with late referral? Thorax 1993;48:925-7.

[117] Jiménez Castro D, Díaz G, Pérez-Rodríguez E, Light RW. Prognostic features of residual pleural thickening in parapneumonic pleural effusions. Eur Respir J 2003;21:952-5.

[118] Vianna NJ. Nontuberculous bacterial empyema in patients with and without underlying diseases. JAMA 1971;215:69-75.

[119] Benfield GF. Recent trends in empyema thoracis. Br J Dis Chest 1981;75:358-66.

[120] Lemmer JH, Botham MJ, Orringer MB. Modern management of adult thoracic empyema. J Thorac Cardiovasc Surg 1985;90:849-55.

[121] Mandal AK, Thadepalli H. Treatment of spontaneous bacterial empyema thoracis. J Thorac Cardiovasc Surg 1987;94:414-8.

[122] Wehr CJ, Adkins RB Jr. Empyema thoracis: a ten-year experience. South Med J 1986;79:171-6. 
Tableaux :

\begin{tabular}{|c|c|c|c|}
\hline Classe & EPPP & Caractéristiques & Traitement évacuateur \\
\hline $\begin{array}{c}\text { Classe } \\
1\end{array}$ & $\begin{array}{l}\text { EPP non } \\
\text { significatif }\end{array}$ & $\begin{array}{l}<10 \mathrm{~mm} \text { sur la radiographie } \\
\text { thoracique (décubitus latéral) }\end{array}$ & Aucun \\
\hline $\begin{array}{c}\text { Classe } \\
2\end{array}$ & EPP typique & $\begin{array}{l}>10 \mathrm{~mm} \\
\text { Glycopleurie }>0,4 \mathrm{~g} / \mathrm{L}, \mathrm{pH}>7,2 \\
\text { ED et culture négatifs }\end{array}$ & Aucun \\
\hline $\begin{array}{c}\text { Classe } \\
3\end{array}$ & $\begin{array}{l}\text { EPP en voie de } \\
\text { complication }\end{array}$ & $\begin{array}{l}7,0<\mathrm{pH}<7,2 \text { et/ou } \mathrm{LDH}>1000 \\
\text { et glycopleurie }>0,4 \mathrm{~g} / \mathrm{L} \\
\text { ED et culture négatifs }\end{array}$ & $\begin{array}{l}\text { Ponctions pleurales } \\
\text { évacuatrices }\end{array}$ \\
\hline $\begin{array}{c}\text { Classe } \\
4\end{array}$ & $\begin{array}{l}\text { EPP compliqué } \\
\text { simple }\end{array}$ & $\begin{array}{l}\mathrm{pH}<7,0 \text { et/ou glucose }<0,4 \mathrm{~g} / \mathrm{L} \\
\text { et/ou ED ou culture positifs. } \\
\text { Absence de loculations }\end{array}$ & Drainage thoracique \\
\hline $\begin{array}{c}\text { Classe } \\
5\end{array}$ & $\begin{array}{l}\text { EPP compliqué } \\
\text { complexe }\end{array}$ & $\begin{array}{l}\mathrm{pH}<7,0 \text { et/ou glucose }<0,4 \mathrm{~g} / \mathrm{L} \\
\text { et/ou ED ou culture positifs. } \\
\text { Présence de loculations }\end{array}$ & $\begin{array}{l}\text { Drainage thoracique }+ \\
\text { fibrinolyse intrapleurale }+/- \\
\text { thoracoscopie ou décortication }\end{array}$ \\
\hline $\begin{array}{c}\text { Classe } \\
6\end{array}$ & Empyème simple & $\begin{array}{l}\text { Pus franc } \\
\text { Une seule poche enkystée }\end{array}$ & $\begin{array}{l}\text { Drainage thoracique }+/- \\
\text { décortication chirurgicale }\end{array}$ \\
\hline $\begin{array}{c}\text { Classe } \\
7\end{array}$ & $\begin{array}{l}\text { Empyème } \\
\text { complexe }\end{array}$ & $\begin{array}{l}\text { Pus franc } \\
\text { Poches multiples }\end{array}$ & $\begin{array}{l}\text { Drainage thoracique }+ \\
\text { fibrinolyse intrapleurale } \\
\text { Thoracoscopie ou } \\
\text { décortication souvent requises }\end{array}$ \\
\hline
\end{tabular}

Tableau I : Classification de Light (1995) [36]

EPP : épanchement parapneumonique, ED : examen direct

Tableau II : Classification de l'American College of Chest Physicians (2000) [53]

\begin{tabular}{clllllll}
\hline Catégorie & $\begin{array}{l}\text { Taille de } \\
\text { l'épanchement } \\
\text { pleural }\end{array}$ & $\begin{array}{c}\text { Biochimie } \\
(*)\end{array}$ & $\begin{array}{c}\text { Bactériologie } \\
\text { (ED ou } \\
\text { culture })\end{array}$ & $\begin{array}{c}\text { Risque } \\
\text { d'évolution } \\
\text { défavorable }\end{array}$ & Drainage \\
\hline 1 & $\begin{array}{l}\text { Minime }(<10 \\
\text { mm) }\end{array}$ & et & Inconnu & et & Inconnu & Très faible & Non \\
\hline 2 & $\begin{array}{l}\text { Faible à } \\
\text { modéré } \\
(>10 \mathrm{~mm}, \\
<\text { hémithorax })\end{array}$ & $\underline{\text { et }}$ & $\mathrm{pH}>7,20$ & $\underline{\text { et }}$ & Négatif & Faible & Non \\
& $\begin{array}{l}\text { Important } \\
\text { (>hémithorax }) \\
\text { Loculations } \\
\text { Épaississement } \\
\text { pleural }\end{array}$ & $\underline{\text { ou }}$ & $\mathrm{pH}<7,20$ & $\underline{\text { ou }}$ & Positif & Modéré & Oui \\
\hline 4 & Empyème & & & & & & \\
\hline
\end{tabular}


(*) En l'absence de valeur de pH, les valeurs de glycopleurie peuvent être utilisées avec une valeur seuil de $0,6 \mathrm{~g} / \mathrm{L}$.

ED : examen direct.

Tableau III : Classification de la British Thoracic Society (2010) [54]

\begin{tabular}{lccc}
\hline & $\begin{array}{c}\text { Épanchement } \\
\text { parapneumonique simple }\end{array}$ & $\begin{array}{c}\text { Épanchement } \\
\text { parapneumonique } \\
\text { compliqué }\end{array}$ & Empyème \\
\hline Aspect macroscopique & Clair & Clair ou trouble & Pus \\
\hline $\mathrm{pH}$ & $>7,2$ & $<7,2$ & - \\
\hline $\mathrm{LDH}(\mathrm{UI} / \mathrm{L})$ & $<1000$ & $>1000$ & - \\
\hline Glycopleurie $(\mathrm{g} / \mathrm{L})$ & $>0,4$ & $<0,4$ & Positif \\
\hline $\begin{array}{l}\text { Bactériologie } \\
\text { (Examen direct ou } \\
\text { culture })\end{array}$ & Négatif & Positif & \\
\hline \begin{tabular}{l} 
Drainage thoracique \\
\hline
\end{tabular} & Non & & Oui \\
\hline
\end{tabular}


Tableau IV : Classification du collège des enseignants de pneumologie (2013) [55]

\begin{tabular}{lcc}
\hline & $\begin{array}{c}\text { Épanchement } \\
\text { parapneumonique simple }\end{array}$ & $\begin{array}{c}\text { Épanchement parapneumonique } \\
\text { compliqué (=empyème ou pleurésie } \\
\text { purulente) }\end{array}$ \\
\hline Abondance & Faible & Grande \\
\hline Cloisonnement & Absent & Présent \\
\hline Aspect macroscopique & Clair & Trouble ou purulent \\
\hline pH (discuté) & $>7,2$ & Positif \\
\hline $\begin{array}{l}\text { Bactériologie (examen } \\
\text { direct ou culture) }\end{array}$ & Négatif & Obligatoire \\
\hline $\begin{array}{l}\text { Évacuation liquide } \\
\text { infecté }\end{array}$ & Optionnel & \\
\hline
\end{tabular}


Tableau V: Publications rapportant des séries de pleurésies infectieuses traitées par ponctions pleurales répétées

\begin{tabular}{|c|c|c|c|c|c|}
\hline Auteur & Caractéristiques & $\begin{array}{c}\text { Nombre de } \\
\text { patients }\end{array}$ & Catégorie & Succès & Mortalité \\
\hline Viana [118] & $\begin{array}{c}\text { Monocentrique } \\
1964-1968\end{array}$ & 41 & $\mathrm{NC}$ & $1(2,4 \%)$ & $\begin{array}{c}8 \\
(19,5 \%)\end{array}$ \\
\hline $\begin{array}{l}\text { Benfield } \\
{[119]}\end{array}$ & $\begin{array}{c}\text { Monocentrique } \\
1968-1978\end{array}$ & 24 & $\mathrm{NC}$ & $8(33,3 \%)$ & $\begin{array}{c}3 \\
(12,5 \%)\end{array}$ \\
\hline $\begin{array}{l}\text { Lemmer } \\
{[120]}\end{array}$ & $\begin{array}{c}\text { Monocentrique } \\
1978-1982 \\
\end{array}$ & 4 & $\mathrm{NC}$ & $3(75 \%)$ & $1(25 \%)$ \\
\hline Mandal [121] & $\begin{array}{c}\text { Monocentrique } \\
1972-1984 \\
\end{array}$ & 28 & $\begin{array}{l}50 \% \text { EPP } \\
\text { compliqués }\end{array}$ & $28(100 \%)$ & $0(0 \%)$ \\
\hline Wehr [122] & $\begin{array}{c}\text { Monocentrique } \\
1974-1984\end{array}$ & 27 & $\mathrm{NC}$ & $6(22,2 \%)$ & $2(7,4 \%)$ \\
\hline Storm [72] & $\begin{array}{c}\text { Monocentrique } \\
1984-1989\end{array}$ & 51 & $\begin{array}{c}100 \% \text { EPP } \\
\text { compliqués et } \\
\text { empyèmes }\end{array}$ & $48(94,1 \%)$ & $4(7,8 \%)$ \\
\hline $\begin{array}{l}\text { Ferguson } \\
{[19]}\end{array}$ & $\begin{array}{l}\text { Prospective } \\
1986 \text { - } 1990 \\
\end{array}$ & 46 & 100 \% empyèmes & $19(41 \%)$ & $3(6,5 \%)$ \\
\hline Simmers [73] & $\begin{array}{c}\text { Monocentrique } \\
1999 \\
\end{array}$ & 29 & $\begin{array}{l}\text { EPP compliqués } \\
\text { et empyèmes }\end{array}$ & $25(86 \%)$ & $4(14 \%)$ \\
\hline $\begin{array}{l}\text { Letheulle } \\
\text { [70] }\end{array}$ & $\begin{array}{c}\text { Monocentrique } \\
2013 \\
\end{array}$ & 79 & $\begin{array}{l}\text { EPP compliqués } \\
\text { et empyèmes }\end{array}$ & $64(81 \%)$ & $4(12 \%)$ \\
\hline
\end{tabular}




\section{Figures :}

Figure 1 : Exemple de liquide pleural macroscopiquement purulent (empyème).

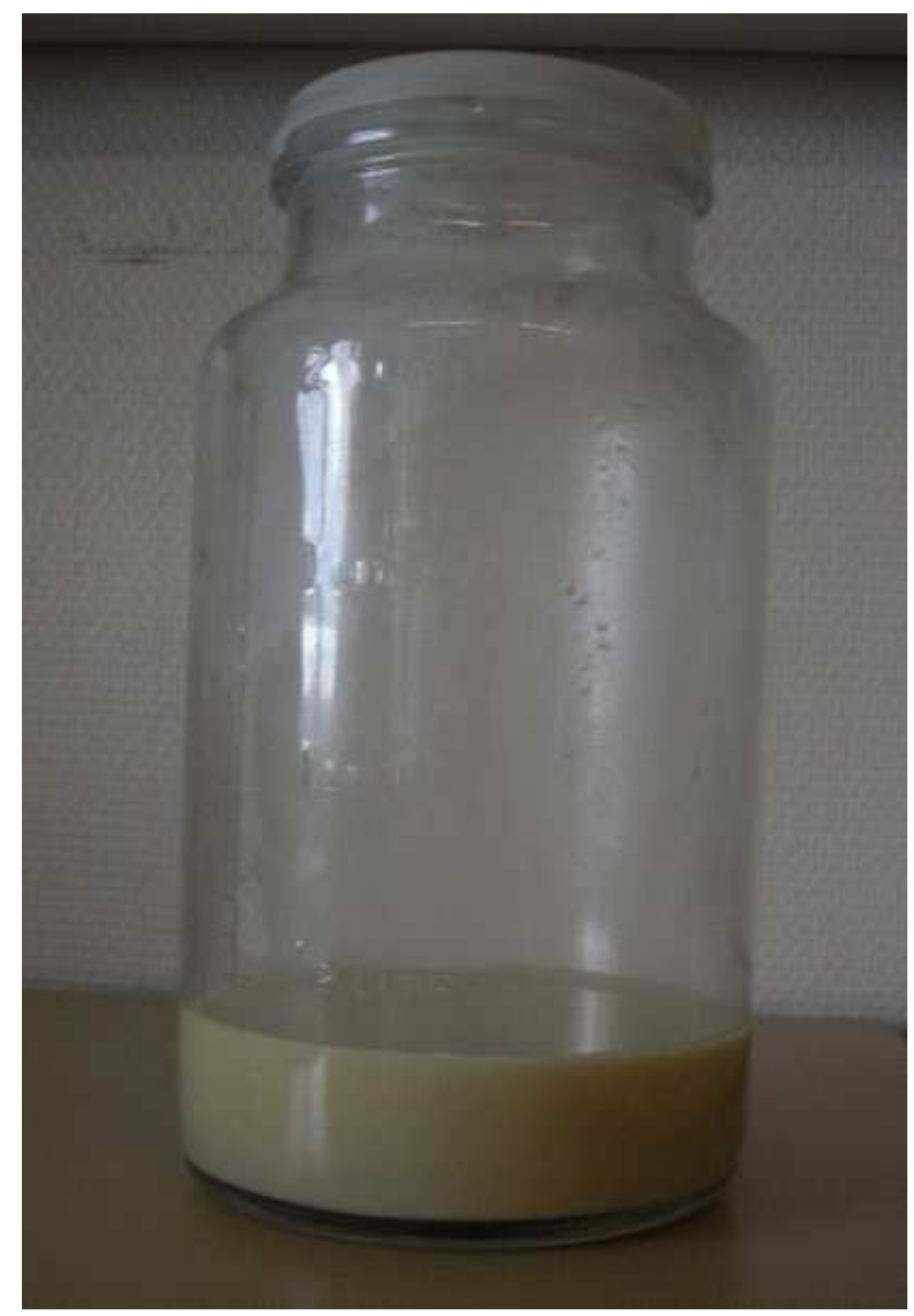

Figure 2: Physiopathologie de la formation d'un épanchement parapneumonique (EPP) 
Figure 3 : Aspect scannographique de pleurésie purulente cloisonnée droite. On notera ici la présence de 3 poches pleurales enkystées.

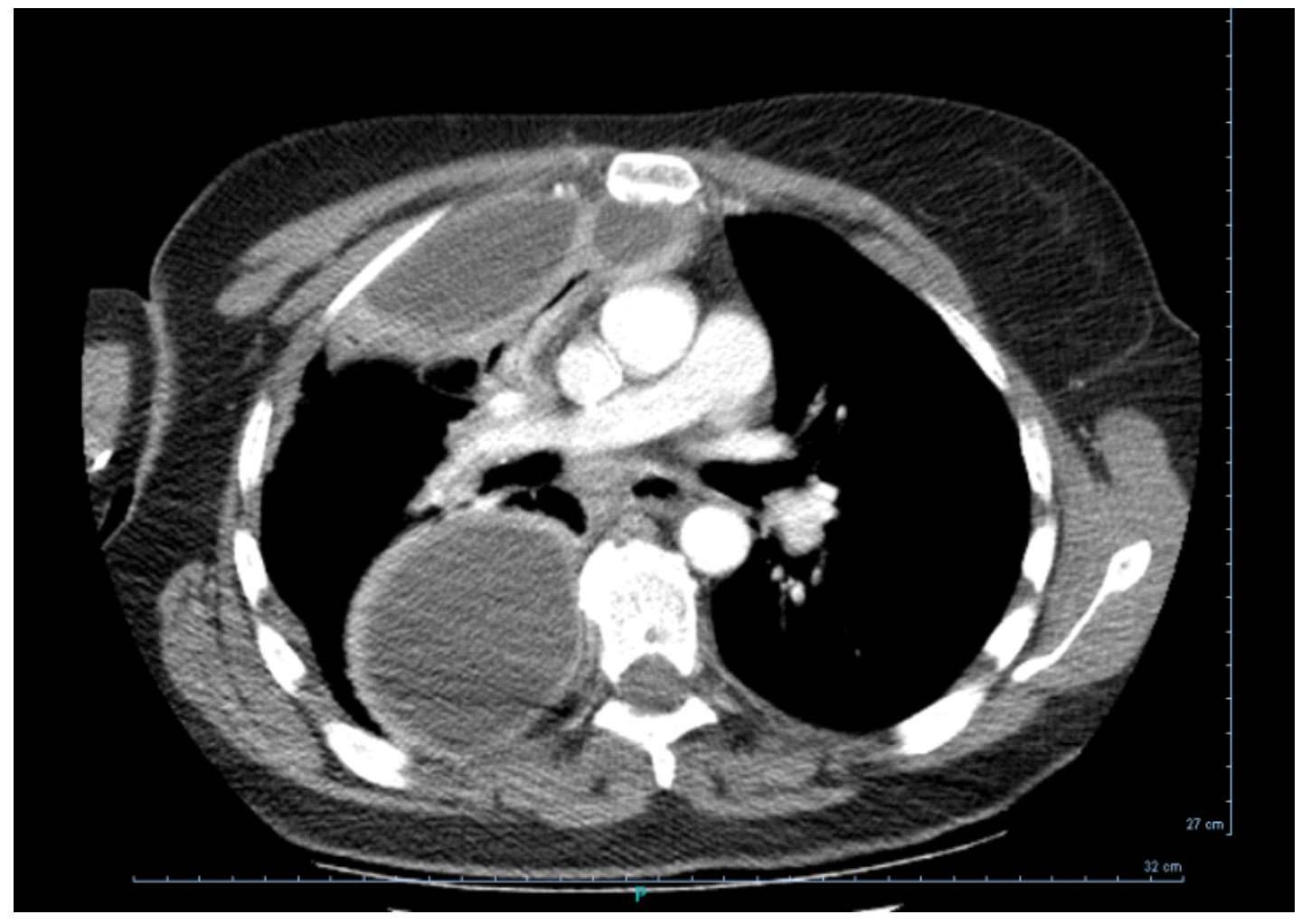

